\title{
Un caso de quiste congénito del ovario, coexistente con anomalias del tracto génito-urinario y digestivo
}

\author{
Por el doctor Eduardo Acosta Bendek, M. D.
}

Trabajo leído en la Sociedad de Obstetricia y Ginecología del Atlántico en la sesión del mes de noviembre de 1954.

Los tumores del ovario, al decir de Eweing, "presentan una diversidad estructural más amplia, una mayor variación individual y una base embriológica e histogenética más compleja que los de cualquier otro órgano, y por esta razón no han podido clasificarse de modo satisfactorio".

Varios son los criterios que han guiado a los distintos autores para hacer una satisfactoria clasificación de los tumores del ovario, teniendo como base su carácter morfológico unas veces, embrológico o histogenético otras sin embargo, muchos de ellos aún desafían cualquier clasificación y aún más todavía: se desconoce el origen de alguno de los más comunes. Guardamos la esperanza que a medida que nuestros conocimientos aumentan en lo que se relaciona a la embriología del ovario e histogenésis de los tejidos que se encuentren en éste, se podrán dilucidar muchos en estos problemas no esclarecidos aún hoy en día.

Los quistes comunes del ovario, dentro de los cuales situamos el nuestro, se ha reportado su frecuencia en un $21 \%$ del total de los tumores del ovario (1). Son de mucha importancia práctica para el ginecólogo y de interés muy relativo para el endocrinólogo, ya que se desconoce actualmente que produzcan hormonas específicas, como también de que su desarrollo sea favorecido por estímulos endocrinos; solamente se ha demostrado que afecta a una glándula que es el ovario. Estos tumores han llamado la atención clesde los tiempos inmemoriales a todos los médicos, a causa del gran tamaño que logran alcanzar y de su gran variedad morfológica y funcional. 
Los quistes congénitos del ovario, cualquiera sea su variedad, no son muy frecuentes, la bibliografía médica mundial registra muy pocos casos, y entre nosotros no he encontrado ninguno publicado en toda la literatura médica que he consultado, creo ser éste el primer caso reportado. De los quistes congénitos ei más común es el Dermoide, con una frecuencia del $10 \%$ de todos los çuistes del ovario (2). El interés de este caso es el de presentar la coexistencia del quiste del ovario, con anomalías del tracto génitourinario y digestivo, ya que en la bibliografía médica consultada no he encontrado uno similar.

\section{CASO REPORTADO}

Se trata de una niña nacida de un parto normal, en el servicio de maternidad "Leopoldina de Santos" del hospital de BaIranquilla, de una madre cuyo pasado histórico no tiene importancia. Al examen clínico la niña presentaba las anomalías siguientes: en la región abdominal se encontraba una gran hernia c.bdominal (exonfalos) del tamaño de una naranja, pudiendo casi ciecir que se trataba de un grado discreto del monstruo Celosomiano. En la región perineal ausencia del ano y en la vulva, los pequeños labios se encontraban unidos por su borde interno formando una especie de bolsa escrotal, en el extremo superior de esta bolsa se encontraba un pequeño orificio, representante del meato por donde salía la orina, encima de éste se hallaba un ligero esbozo de clítoris y prepucio rudimentario. Tanto la cabeza. como los miembros superiores e inferiores y región del tórax eran normales. Se hizo el intento de hacer la reparación de la imperforación del ano cuarenta y ocho horas después del nacimiento con resultados infructuosos. La niña murió a los diez días de nacida.

En la autopsia practicada se encontró: hernia umbilical formada por intestino delgado y epiplón, en la región de la pelvis, ausencia de matriz y vagina, y en la parte lateral de ésta dos oviductos representantes de los conductos de Muller separados en toda su extensión, cuyos extremos inferiores terminaban en la vejiga por un pequeño orificio, muy cerca de la desembocadura de los orificios ureterales (figura número 1), los extremos superiores terminaban en forma de fimbria, en el lado derecho se encontraba un ovario de apariencia normal con sus respectivos ligamentos; en el izquierdo se encontraba un quiste correspondiente a dicho ovario, del tamaño de un limón grande, de superficie lisa, tensa y muy vascularizado (figura número 2), el cual se extirpó y se envió 


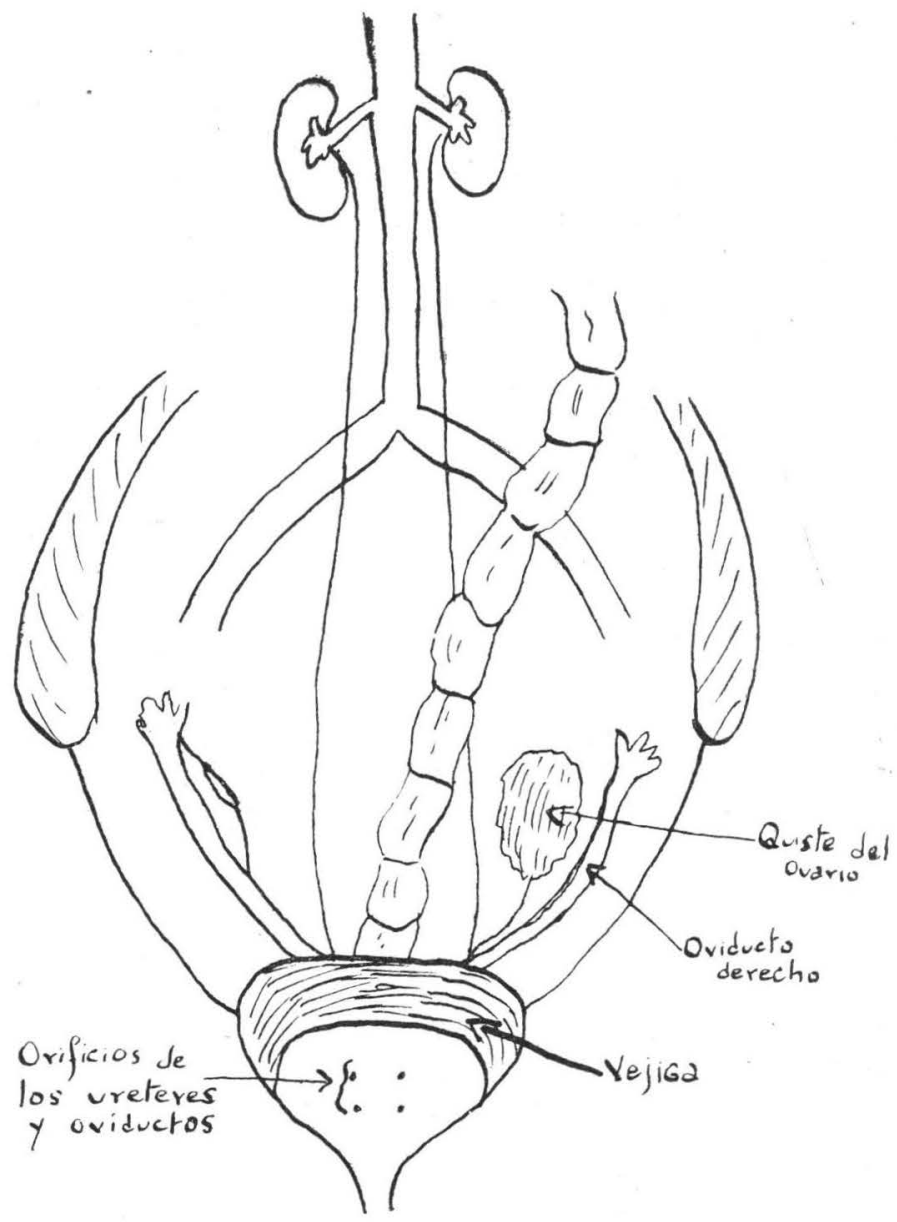

\section{Fig. \#1}

para su respectivo estudio histopatológico, cuyo reporte más adelante transcribiremos. La vejiga más grande que el tamaño normal y de paredes hipertróficas, en la base de ésta se apreciaban 4 orificios (figura número 1), dos correspondientes a los ureteres y los otros dos a los conductos de Muller, cuya permeabilización se comprobó con la introducción por dicho orificio de un pequeño estilete. El recto terminaba ciegamente en la cara posterior y superior de la vejiga, y entre los dos conductos de Muller. Tanto los riñones como los ureteres y demás órganos internos eran de aspectos normales. La falsa bolsa escrotal se abrió, encontrándose un pequeño conducto representante de uretra y vagina que comunicaba directamente con la vejiga. 


\section{DESCRIPCION MACROSCOPICA}

La pieza consiste en un quiste de forma ovoide que mide 7 centímetros en su mayor diámetro. La pared es fibrosa, muy delgada y transparente y se ven en ella numerosos vasos sanguíneos. El contenido es una substancia de color gris claro, de consistencia y aspecto gelatinoso. Tanto la superficie interior como la exterior son lisas y libres de excrecencias o protuberancias. No se aprecia revestimiento epitelial. En el contenido no hay pelos ni sebo. En un sitio de la superficie exterior está presente un segmento de oviducto de 2 centímetros de longitud. No se puede reconocer tejido ovárico. También en el contenido se ven unas estrías de color amarillento.

\section{Descripción microscópica:}

Los cortes practicados sobre la pared del quiste muestran tejido conjuntivo fibroso en el que se ven vasos sanguíneos muy dilatados y pequeños focos hemorrágicos. No se puede distinguir revestimiento epitelial. El contenido se compone de substancia amorfa teñida por la eosina y masas de leucocitos polimorfonucleares. El oviducto también presenta marcada hiperemia.

El cuadro histológico solamente sugiere el diagnóstico de quiste simple o quiste de retención. La ausencia de revestimiento epitelial y de glándulas y estructuras anexas al tejido epidérmico impiden pensar que se trate de un quiste dermoide cuya torsión cel pedículo haya producido atrofia o modificación del epitelio, pues en tal caso no habrían desaparecido estructuras como pelos y depósitos de sebo.

Diagnóstico: quiste simple del ovario.

\section{COMENTARIOS:}

Con relación al diagnóstico del anatomopatólogo de "quiste simp'e del ovario", ya que la falta de revestimiento epitelial y ausencia de glándulas de éste le impidió hacer un diagnóstico más preciso, cabe hacer la observación, que la falta de revestimiento epitelial posiblemente pudo haber sido ocasionada por la presión interna del quiste y a esto le agregamos el tiempo que éste duró (quince meses) antes de ser enviado al examen histopatológico. En todo caso queda también la posibilidad de catalogarlo como un 


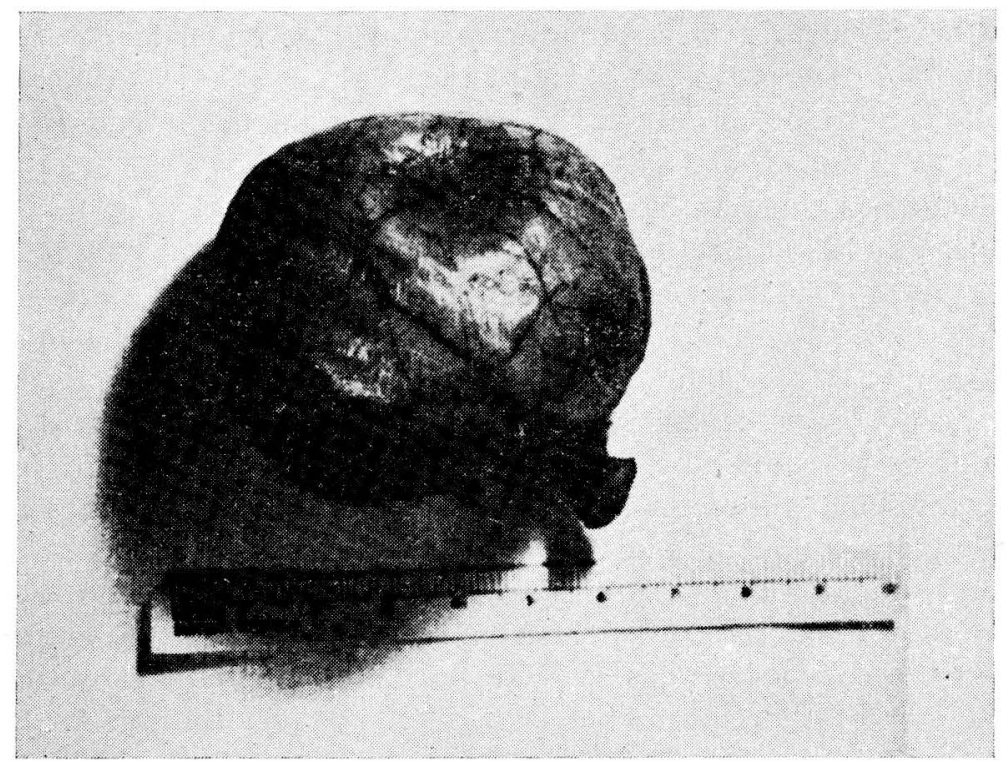

Figura No 2

simple cistoadenoma, que por el aspecto gelatinoso de su contenido bien pudiera ser mucoide. Es aceptado actualmente por unanimidad que los cistoadenomas serosos tienen su origen en el epitelio germinatiovo del ovario al invaginarse, y los pseudomucosos poco se sabe sobre su patogenia, la mayoría de los autores aceptan como tesis más probable le da derivarse de restos embrionarios (2).

Las características morfológicas de los tumores del ovario son sumamente variadas, debido a que en el ovario pueden desarrollars infinidad de neoplasias fundamentalmente distintas. Con relación al tamaño los encontramos desde las formaciones microscópicas hasta los tumores más voluminosos que jamás se puedan cesarrollar en el ser humano. Los tumores ováricos son frecuentemente bilaterales, en un principio benignos pueden transformarse en malignos posteriormente o sufrir alteraciones degenerativas, como necrosis, calcificaciones, etc.

Embriológicamente las gonadas (ovario y testículos) tienen $\mathrm{su}$ origen en la formación conocida con el nombre de "cresta genital" (3), la gonada así formada está sexualmente indiferenciada hasta la séptima semana aproximadamente de la vida fetal; de aquí en adelante comienza a adoptar las características definitivas masculinas o femeninas. 
Con respecto a las anomalías presentadas en el tracto Génitourinario y Digestivo me permito recordar algunas fases del desarrollo embriológico de estos órganos para así poder comprender mejor su histogenésis.

Tenemos que las Trompas de Falopio, la Matriz y la parte superior de la vagina tienen su origen en los conductos de Muller. Koff pudo identificar estos conductos en embriones de solo un milímetro de longitud, correspondiente a una edad de ocho semanas (3), lo que viene a demostrar la diferenciación muy temprana en la vida embrionaria de las estructuras génitourinarias. Cuando se presenta una inhibición completa del desarrolio de los Conductos de Muller en la fase primitiva, es decir, cuando falta la completa unión de éstos, se produce una anomalía típica consistente en ausencia de útero y parte interna de la vagina. Las trompas de Falopio se vuelven unas estructuras rudimentarias completamente separadas una de otra y se encuentran situadas en la parte lateral de la pelvis, viniendo a terminar en la línea media detrás de la vejiga ciegamente, caso exactamente igual al reportado en este escrito, con la diferencia de que el extremo inferior de los oviductos terminaban abiertamente en la vejiga y no ciegamente.

Con lo que respecta a los órganos genitales externos tenemos que se originan en el tubérculo genital, éste presenta un extremo redondeado y libre que en la mujer viene a formar el clitoris. A su lado se encuentran los pliegues y rodetes genitales que son los que dan origen a los pequeños y grandes labios (5). Tanto la uretra, vagina y órganos genitales externos se desarrollan juntos $y$ tienen en la mujer adulta relaciones anatómicas y funcionales de tipo muy íntimo. El seno urogenital es el área superficial donde se abre la uretra y vagina; esto nos explica las aliomailias presentadas en dichos órganos en nuestro caso.

La vejiga se forma por división de la cloaca, de la cual la mitad anterior constituirá la vejiga y la posterior el recto, esto nos demuestra que la anomalía registrada en el presente caso fue causada posiblemente por detención del desarrollo de dichos organos, ignorándose la causa íntima de este fenómeno.

En lo que hace relación con la hernia umbilical tenemos que el asa embrionaria del mesogastrio al comienzo de la vida embrionaria penetra en el cordón umbilical para volver posteriormente a la cavidad abdominal seguido de ía oclusión del anillo umbilical; cuando esto no sucede da origen a la hernia umbilical. 


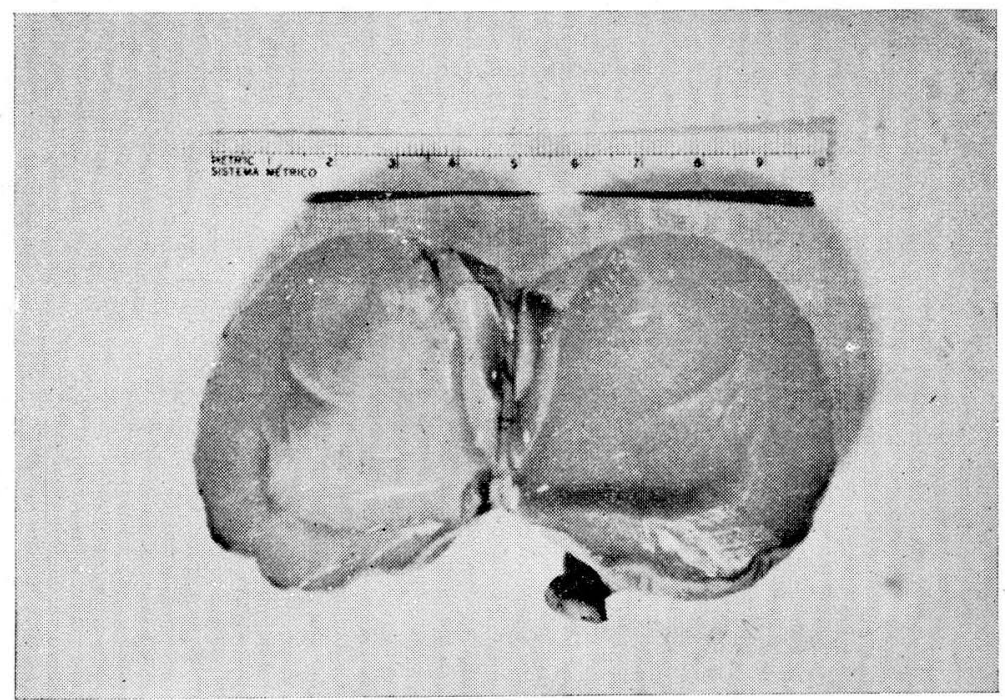

Figura $N^{\circ}$ ? 3

La imperforación del ano era grado tres. Por falta del desarrollo del intestino posterior no existía la ampolla rectal y el canal anal, quedando el fondo de saco cólico por encima del revestimiento peritoneal y unido a la vejiga. La frecuencia de la imperforación del ano según algunos autores es de uno por cada cinco mil nacimientos (7).

\section{RESUMEN:}

Se registra un caso de quiste congénito del ovario, coexistente con hernia umbilical, ausencia de matriz, vagina, imperforación del ano, anomalías de los órganos genitales externos y ausencia de ampolla rectal y canal anal. Además se hace un breve comentario sobre la histogénesis de las distintas anomalías presentadas en ei mencionado caso (1).

(1) Hago manifiesto mi agradecimiento al doctor Guillermo López Escobar por la colaboración prestada en el presente escrito. 


\section{BIBLIOGRAFIA:}

1) -López Escobar Guillermo. "Tumores del Ovario". Publicación de la Soc. Médico-Quirúrgica. Lombana Barreneche. 1952. Junio.

2) - Selye Hans. Endocriminología. Salvat, Ed. S. A. Madrid. 1952.

3)-Wharton R. Lawrence, Ph. E., M. D. Ed. Hispanoamérica .Méjico. 1952. Ginecología.

4) - Crossen and Crossen. Ed. Hispanoamericana, S. A. México. 1950. Enfermedades de las mujeres.

5)-Costero Isaac. Tratado de Anatomía Patológica. Ed. Atlante. 1946.

6)-Ewing J. Neoplastic Diseases. W. B. Sauders and. Co. Ed. Filadelfia 1934.

7)-Max Thorek. Modern Surgical Technic. Second Edition. J. B. Lippincott. Philadelphia. 1952.

8) -Newell W. Philpott, and Jack E. Ross. Am. J. Obst. \& Gynec. 68: $285,1954$.

9) -Prof. Achible De Fabii. La Clínica Obstétrica. № 9: 514-16. 1937.

10) - Luigi Celleti. Cuaderno de Obstetricia. Ed. Ateno. Roma. Págs. 14-17. 1947.

11) —Ovidio Timpanaro. Dermoide Ovárico Gigante. La Clínica Obstétrica. № 7: 443, 1932.

12) - Guido Berti. Contributo allo studio istologico delle vegetagiones papillari nei cistomi ovari. 1934.

13) -Jehan Shah Saleh. The youngest patient with a granulosa cell tumor. Am. J. Obst. \& Gynec. 67: 679, 1954.

14)-Mario Schteingart. Endocriminología. Ed. Bibliográfica Argentina. 719: 726. 1953. 